\title{
On the Biology of Sagitta. III. A Further Observa- tion on the Growth and Breeding of Sagitta setosa in the Plymouth Area.
}

By

\author{
F, S. Russell D.S.C., B.A., \\ Naturalist at the Plymouth Laboratory.
}

With 1 Figure in the Text.

IN a previous paper an account was given of the breeding and growth of Sagitta setosa throughout a year (2). The results appeared to show that the last spawning took place in October and the resulting offspring lived through November and December without maturing and that by February there were indications that a number were spawning. At the end of the following April and beginning of May a complete spawning population was formed. Owing to the large size at which these matured it was assumed (2, p. 148) that they had been the offspring of adults spawning in February. The true trend of events was however by no means clear as the increase in average size from January to May was very even (2, Plate II). There was a distinct difference at this period between S. elegans and $S$. setosa. In $S$. elegans a spawning population of individuals all about the same length was produced in February which apparently gave rise to a brood which had grown to a large size by April and May, and the change in size from February to May was much more abrupt than in S. setosa (1, Plate I). It was clear that while the February curve for S. elegans showed very little variation in size for the majority of the population caught, the population in May tended to be very widely dispersed. In $S$. setosa, on the other hand, there was a gradual narrowing down of the dispersion until a spawning population with little variation in length was produced by May.

It was felt that it might be worth while examining this period for another year for $S$. setosa, and accordingly observations were made in exactly the same way as previously from December, 1931, to May, 1932.

The results are given in Figure 1 where the curves show the percentage length-distribution of samples of S. setosa taken in oblique hauls of the ring-trawl on the dates given. On these curves are superimposed the stages of development of the Sagitta as explained in Plate I of 1 . This 
M M. SAGITTA SETOSA.

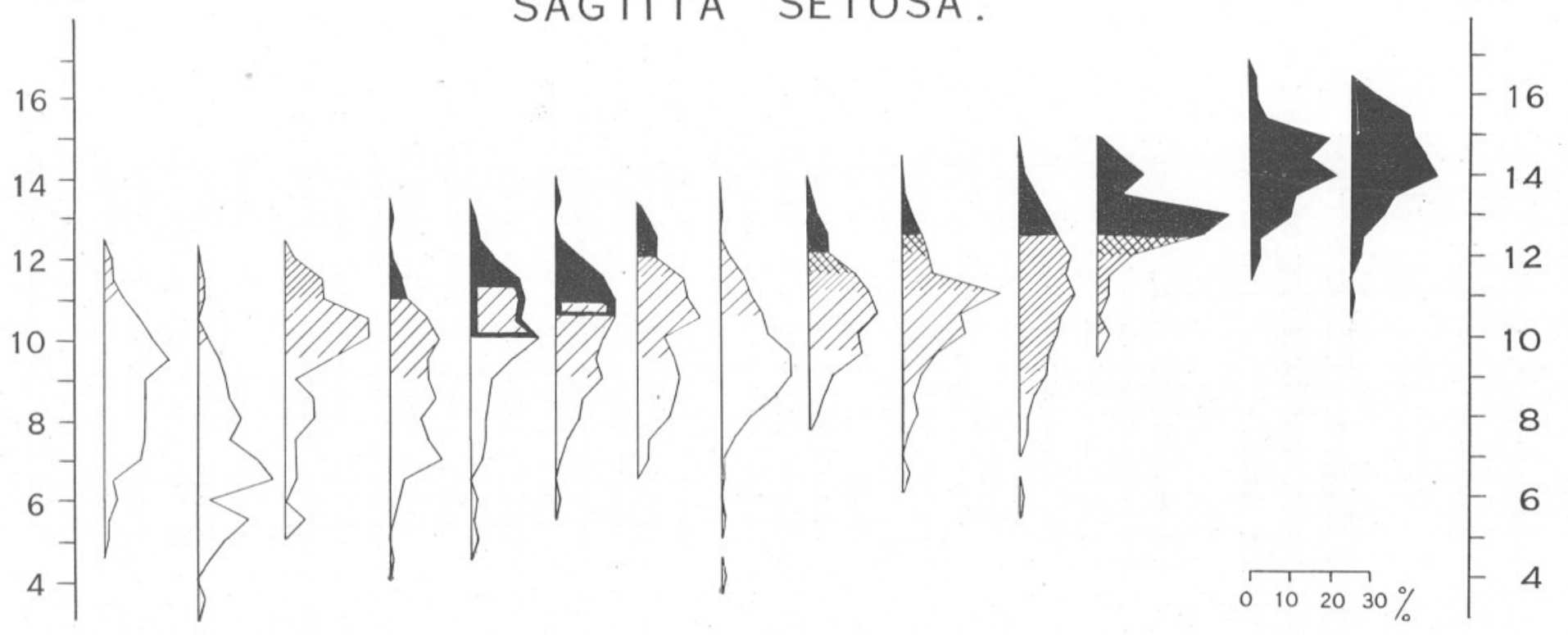

1932

\section{JANUARY}

| FEBRUARY |

MARCH

| APRIL |

MAY

12

19

26

$10 \quad 17$

FIG. 1.- The percentage size distribution of Sagitta setosa caught in the ring-trawl on the days given. The black, cross-hatched, and shaded areas represent the various stages of development. For further explanation, see 1, Plate I. 
figure shows, as in the previous results (2, Plate II), the gradual closing up of the length-distribution of the population until apparently a spawning population was formed in May. It appears, however, on this occasion that there was a much smaller proportion of ripe individuals in February and that these tended to disappear in March, there being a comparative absence of the individuals above 11 to $12 \mathrm{~mm}$. in length which appeared in the previous year. From an examination of Figure 1 it is open to question whether the May spawning population may not be formed of a mixture of the offspring of the October spawners which have lived right through the winter and not matured until May, and of the offspring of the February spawners which have grown quickly to a large size by May. It seems natural that any offspring produced in February must have grown to form the May adults as there is no indication of any small unripe individuals in May. On the other hand, the ripening in February may have been premature and the spawning a failure.

It seems that the method adopted here is inadequate to clear this point up and that similar observations should be supplemented by finer tow-nettings to search for eggs and very young stages in February and March.

The confirmation given by the general trend of the curves that the complete spawning population is not formed until May is however striking and as such constitutes a distinct difference from the trend of events during the same period of the year for $S$. elegans. It is felt that it is unnecessary to print the tables of measurements here as in the previous reports ( 1 and 2 ) since Figure 1 gives all the necessary data. The actual numbers caught since the last date given in the previous publications are inserted in Table I.

\section{REFERENCES.}

1. Russell, F. S. On the Biology of Sagitta. The Breeding and Growth of Sagitta elegans Verrill in the Plymouth Area, 1930-31. Journ. Mar. Biol. Assoc., N.S., Vol. XVIII, No. 1, pp. 131-146, 1932.

2. — On the Biology of Sagitta. II. The Breeding and Growth of Sagitta setosa J. Mïller in the Plymouth Area, 1930-31, with a Comparison with that of S. elegans Verrill. Ibid., Vol. XVIII, No. 1, pp. 147-160, 1932. 


\section{TABLE I.}

Total Numbers of $S$. elegans and $S$. setosa IN HALF-HOUR Oblique Ring-trawl Collections.

1931.

Sept. 17th

, 24th

Oct. 1st

,., 8th

, 15th

," 22nd

,, 29th

Nov. 25th

Dec. 4 th

., 9th

,, 16th

, 22nd

, 30 th 1932.

Jan. 7 th

,, 12th

\begin{tabular}{|c|c|c|c|}
\hline $\begin{array}{c}\text { S. elegans. } \\
420\end{array}$ & $\begin{array}{c}\text { S. setosa. } \\
28,530\end{array}$ & $\begin{array}{r}19 \\
\text { Jan. }\end{array}$ & $\begin{array}{l}32 . \\
19 \text { th }\end{array}$ \\
\hline 200 & 12,560 & & $26 \mathrm{th}$ \\
\hline 20 & 4,880 & Feb. & 3rd \\
\hline+ & 2,520 & , & 10th \\
\hline - & 8,780 & & 17 th \\
\hline 20 & 9,300 & Mar. & 9 th \\
\hline 20 & 8,040 & , , & 16th \\
\hline 20 & 2,340 & , & $23 \mathrm{rd}$ \\
\hline 15 & 180 & ," & 30 th \\
\hline 50 & 730 & April & 15 th \\
\hline 320 & 1,760 & ,, & 14th \\
\hline 60 & 1,090 & , , & 20 th \\
\hline 10 & 665 & M̈av & $\begin{array}{r}28 \text { th } \\
4 \text { th }\end{array}$ \\
\hline 60 & 530 & , & 11th \\
\hline 250 & 410 & & 19th \\
\hline
\end{tabular}

S. elegans. S. setosa.

124

$300 \quad 415$

$195 \quad 260$

$128 \quad 505$

$90 \quad 535$

- $\quad 1,550$

$-2,810$

119
-

$\begin{array}{lr}5 & 248 \\ -\quad 700\end{array}$

- 11

3

- 11

$-284$

599 